\title{
Grammatical Gender in Arabic and Hawrami
}

\author{
Mahdi Sadjadi \\ Ph.D in linguistics \\ University of Tehran, \\ Tehran, Iran
}

\begin{abstract}
Grammatical gender is arguably the most puzzling and fascinating of all grammatical categories that is central and pervasive in some languages and totally absent in others. The aim of this article is to investigate the similarities and differences in grammatical gender between Moroccan Arabic, one of the west Semitic languages, and Hawrami, one of the new northwestern and endangered Iranian languages, belonging to two different language families, i.e. Semitic and Indo-European, within the framework of contrastive analysis. To this end, the written sources in this connection have been used. Moreover, the author is the native speaker of Hawrami and has used his linguistic intuition where necessary. Data contrast indicates that in both languages: there are two grammatical genders (masculine and feminine); all nouns are either masculine or feminine; the unmarked grammatical gender is masculine; the grammatical gender of the noun is determined by its final phone (and stress position in Hawrami); adjectives, verbs, and personal pronouns agree with nouns in grammatical gender. Consequently, the grammatical gender assignment system of both languages is formal, i.e. phonological and therefore overt. There are also some differences between the two languages. The most important one is that only singular nouns have grammatical gender distinction in Hawrami, whereas both singular and plural nouns have this distinction in Moroccan Arabic. The results of the research can be used in language learning and comparative and historical linguistics.
\end{abstract}

Keywords: Moroccan Arabic, Hawrami, Grammatical Gender, Contrastive Analysis

\section{Introduction}

Grammatical gender is arguably the most puzzling and fascinating of all grammatical categories. It is a topic which interests non-linguists as well as linguists and it becomes more fascinating the more it is investigated. In some languages grammatical gender is central and pervasive, while in others it is totally absent (Corbett, 1991: 1).

The main purpose of contrastive analysis is to provide an overview of the similarities and differences of two or more languages. The aim of th present article is to investigate the similarities and differences in grammatical gender between Arabic and Hawrami, belonging to two different language families, i.e. Semitic and Indo-Eurpean, within the framework of contrastive analysis, since both languages possess this grammatical category. To this end, the written sources in this regard have been used. Moreover, the author is the native speaker of Hawrami and has used his linguistic intuition where necessary. As this subject has not been focused on so far, its results can lead to an insight into the similarities and differences in grammatical gender between the two languages and also pave the way for further studies concerning the domain.

The variety of Arabic studied here is Moroccan Arabic (ddariža). It is the local Arabic dialect spoken in Morocco, the westernmost country of North Africa. Like other Arabic vernaculars, Moroccan Arabic is not used for written purposes but only for informal and mundane communication. It is spoken by more than 20 million people (including second language users), i.e. about $90 \%$ of the Moroccan population. Genetically, Moroccan Arabic belongs to the West Semitic branch of the Afroasiatic family of languages. Like other Semitic languages, it has a fairly rich inflectional and derivational morphology (Hellinger \& Bußmann, 2001: 27, 28).

Hawrami, also called Gorani, spoken in some parts of Iran, Iraq (mainly around the borders), and Turkey (known as Zazaki) belongs to the northwestern branch of new Iranian languages and according to UNESCO ${ }^{\text {, }}$ is one of the endangered Iranian languages. It is spoken by some 1.5 million Hawrams or Gorans, mostly Muslims. As Mackenzie (1966: 3,4) points out, Hawrami forms an island in a Kurdish sea and is probably the most archaic and best preserved language.

\footnotetext{
${ }^{1}$ www.unesco.org/languages-atlas/
} 
The structure of the paper is as follows. In addition to this introductory section, it consists of three others. In section 2, the category of grammatical gender and its properties are discussed in general. In sections 3 and 4, grammatical gender in Arabic and Hawrami is described respectively. In section 5, the conclusions (similarities and differences in grammatical gender between Arabic and Hawrami) arrived at in the article, are recapitulated and also the fields in which the results of the article can be applied, are mentioned.

\section{Grammatical Gender}

In many languages, nouns fall into different grammatical genders or noun classes. Typically, the classification is essentially grammatical, and may have only a loose correlation- or no correlation at all- with the semantic properties of the nouns (Tallerman, 2011: 51). Grammatical genders are classes of nouns reflected in the behavior of associated words. A language may have two or more such classes or grammatical genders. The classification frequently corresponds to a real-word distinction of sex, at least in part, but often too it does not (Corbett, 1991: 1).

The determining criterion of grammatical gender is agreement; this is the way in which the grammatical genders are reflected in the behavior of associated words. Grammatical gender agreement is important for two reasons: first, it is the way in which grammatical gender is realized in language use; and second, as a consequence, grammatical gender agreement provides the basis for defining grammatical gender and for establishing the number of grammatical genders in a given language. While there is a broad consensus on the core cases of agreement, there is no generally accepted definition. A working definition is provided by Steele (1978: 610):

The term agreement commonly refers to some systematic covariance between a semantic or formal property of one element and a formal property of another. For example, adjectives may take some formal indication of the number and gender of the noun they modify.

Saying that a language has three grammatical genders implies that there are three classes of nouns which can be distinguished syntactically by the agreement they take. This is the generally accepted approach to grammatical gender. Agreement in grammatical gender may occur in a wide range of agreeing elements: adjectives, demonstratives, articles, numerals, possessives, participles, verbs, relative pronouns, personal pronouns, adverbs, adpositions, and complementizers.(Ibid: 4, 105).

An intriguing question, which interests non-linguists as well as linguists, is the way in which nouns are allotted to different grammatical genders. The type of question at issue is how speakers know that, for example, the word for «house» is masculine in Russian, feminine in French and neuter in Tamil. The way in which native speakers allocate nouns to grammatical genders is called "grammatical gender assignment". Thus native speakers have the ability to work out the grammatical genders of a noun; models of this ability are called "assignment systems". Assingment may depend on two basic types of information about the noun: its meaning (semantics) and its form. Information about form may in turn be of two types: word-structure, comprising derivation and inflection (morphology), and sound-structure (phonology). In semantic systems, the meaning of a noun is sufficient to determine its grammatical gender: thus «house» in Tamil is neuter because it does not denote a human. In formal systems, the meaning of a noun is not adequate to determine grammatical gender on its own. The grammatical gender of the noun is determined instead by formal assignment rules, that is, rules which depend on the form of the noun involved rather than on its meaning. These rules are of two types: morphological and phonological. Morphological rules relate to word-structure. Morphological systems are connected to semantic systems in two ways. First, they always have a semantic core. There is no purely morphological system; the morphological rules assign the nouns in the semantic residue to grammatical genders, that is, they are required where semantic rules fail. And second, they may also overlap with the semantic rules. This happens regularly in derivational morphology. Take the Russian word «šotlandec= Scotsman». Nouns formed with suffix «-ec» are masculine; but more importantly, «šotlandec» is masculine because it denotes a male. On the other hand, there are instances where morphology and semantics do not necessarily overlap; an example is declensional type. «house» can be assigned to the masculine grammatical gender in Russian, given the declensional type to which it belongs. Phonological systems relate to sound-structure. The grammatical gender of a noun is determined by usually its final phone. Hence «maison/

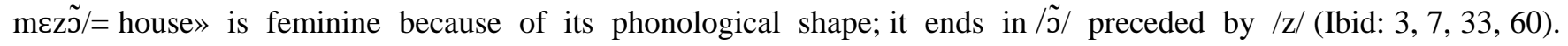
Languages in which the grammatical gender of a noun is evident from its form are often described as having "overt" grammatical gender; those where grammatical gender is not shown by the form of the noun have "covert" grammatical gender. Clearly, then, languages with formal assignment systems are those with overt grammatical gender (Ibid, 62) 


\section{Grammatical Gender in Arabic}

Moroccan Arabic differs on many structural levels from "Literary" Arabic, i.e. Classical and Standard Arabic. Phonologically, Moroccan Arabic has deleted or reduced many vowels that are present in these two varieties. Compare, for instance, Moroccan Arabic «drəb= he hit.» to Literary Arabic «daraba= he hit.». On the morphological level, Moroccan Arabic has dispensed with the dual number (although not entirely) and case marking inflections that are present in Literary Arabic. It has also neutralized the grammatical gender distinction in the third person plural and the second person singular in the perfective tense. On the lexical level, Moroccan Arabic, like the other North African dialects (known also as Maghrebin), namely, Tunisian and Algerian Arabic, contains a substantial number of French words and phrases as a result of their contact with French, the former colonial language. This not only distinguishes them from Literary Arabic but hinders their comprehension by Arabic speakers whose dialects were not essentially influenced by French, such as Jordanian Arabic, Iraqi Arabic and Saudi Arabic, among others. Hence, mutual intelligibility between Moroccan Arabic and other Arabic dialects decreases the further east one travels. However, all of these dialects are similar and therefore intelligible on the more formal, "high" level of the Arabic dialects continuum, i.e., Literary Arabic (Hellinger \& Bußmann: 2001: 30, 31).

The grammatical gender system of modern Moroccan Arabic differs in certain respects from Classical Arabic. Moroccan Arabic has two grammatical genders, feminine and masculine. Only feminine words are morphologically marked for grammatical gender, as most, but not all of these, carry the feminine suffix «-a». Masculine words, on the other hand, carry a zero suffix, they are thus unmarked for grammatical gender. Nouns in Moroccan Arabic are either feminine (e.g., šəzr-a $=$ tree, wsad- $a=$ pillow, kəbd-a $=$ liver) or masculine (e.g., kbrsi= chair, miləf=

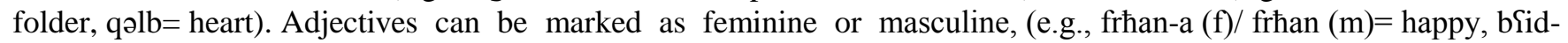
$\mathrm{a}(\mathrm{f}) / \mathrm{bafid}(\mathrm{m})=$ far) and they must agree in gender with the noun they modify.

(1) a. zlaf-a kbir-a

bowl-FEM big-FEM

'a big bowl'

b. țəbsil kabir

plate-MASC big-MASC

'a big plate'

Note that in some cases, nouns in Moroccan Arabic do not end in «-a», but are nevertheless grammatically feminine (e.g., dar= house, bnt= girl), as are most body parts that come in pairs, such as (jod $=$ hand, fin $=$ eye, wdən= ear). In this case, adjectives provide information about the noun's grammatical gender class, as in (2):
(2) 1 -jəd
l-ișr-a

DET-hand.FEM

DET-left-FEM

'the left hand'

(Ibid: 31$)$

Adjectives are not the only part of speech that must agree with nouns in gender and number; pronouns, verbs, and prepositions must also meet this requirement. However, this is not true for the definite article «l-», the only article in Moroccan Arabic, which is indifferent to both gender and number, Let's consider the following example:
(3) a. wssx-at
dik
1-basl-a
ћwajž-ha.

dirty-3PF.FEM.SG that.FEM

DET.turbulent-FEM clothes-her

'That turbulent girl dirtied her clothes.'

b. wssəx dak hasl hwajž-u.

dirty.3PF.MASC.SG that.MASC DET-turbulent.MASC clothes-his

'That turbulent boy dirtied his clothes.'

(Ibid: 32) 
There are several ways of converting a singular form into the plural in Moroccan Arabic; however, patterns of pluralization are complex. In general, Moroccan Arabic distinguishes between two main plural forms for nouns and adjectives; the "sound" and the "broken" plural. The pair "sound" versus "broken" plural is commonly used in the literature to differentiate plurals formed by suffixation (i.e., sound plural) from those formed by internal stem changes (i.e., boken plural). Thus, in the sound plural, feminine and masculine nouns are each assigned different suffixes. The masculine plural form is achieved adding «-in» or «-a» to the masculine singular, (e.g., mufllim (m.sg) $($ male $)=$ teacher, mufllim-in $(\mathrm{m} . \mathrm{pl})(\mathrm{male})=$ teachers, bnnaj $(\mathrm{m} . \mathrm{sg})(\mathrm{male})=$ construction worker, bnnaj-a (m.pl) (male)= construction workers), whereas the sound plural for feminine forms is achieved by adding «-t» to the feminine singular noun or adjective, (e.g., mufllim-a (f.sg) (female)= teacher, mufllim-a-t (f.pl) $($ female $)=$ teachers). The broken plural, on the other hand, is formed by applying internal modification to the stem: (tbsil $(\mathrm{m} . \mathrm{sg})=$ plate, tbasəl $(\mathrm{m} . \mathrm{pl})=$ plates, wsad-a $(\mathrm{f} . \mathrm{sg})=$ pillow, wsajd $(\mathrm{m} . \mathrm{pl})=$ pillows $)$. The case of the broken plural is interesting because it may change the gender of a noun from feminine to masculine as it changes its number. Again it is the masculine inflection on the adjective that provides such information (Ibid: 32).

In principle, grammatical and lexical-referential gender may correspond in human nouns. Thus, human nouns referring to females usually end in «-a» and are feminine, (e.g., mra= woman, bnija= little girl), while those referring to males have no special ending and are masculine, (e.g., ražəl= man, wlijəd= little boy). This is clearly illustrated in kinship terms such as (walid $(m)=$ father, walid-a $(f)=$ mother, $x a l(m)=$ maternal uncle, $x a l-a$ $(\mathrm{f})=$ maternal aunt, fəm $(\mathrm{m})=$ paternal uncle, $\mathrm{Smm}-\mathrm{a}(\mathrm{f})=$ paternal aunt $)$. The same holds for general human nouns, i.e., non-kinship terms, and those which do not have lexical gender, such as (țbbax $=$ cook, tbbax-a $=$ cook (female). Similarly, occupational titles express gender distinctions via grammatical gender, for instance, male lawyer is «muhami», whereas a female lawyer is «miћamij-a». Loan words are no exception, they too follow the same pattern, (e.g., fromli (male) $=$ nurse, fromli-a (female) $=$ nurse) (Ibid: 33, 34).

Personal pronouns in Moroccan Arabic belongs to two types, independent and dependent pronouns. Both types of pronouns are differentiated for gender of referent. Independent subject pronouns such as «huwa= he» and «hija= she» are reserved primarily for emphasis or clarity since the verb form itself usually indicates its subject. Dependent pronouns are clitics that attach to verbs, (e.g., «-t-» (3sg imperfective feminine: ka-t-ktəb= she is writing; «-at» (3sg perfective feminine: $k t a b-a t=$ she wrote; $«-j-»(3 s g$ imperfective masculine: $k a-j-k t ə b=h e$ is writing; the perfective masculine is not morphologically marked: ktəb). The masculine clitic that attaches to nouns and prepositions is «- $\mathrm{u} »(\mathrm{dar}-\mathrm{u}=$ lit. house his= his house), the feminine clitic is «-ha» (dar-ha= lit. househer= her house). Generic «he» in Moroccan Arabic is thus conveyed through the use of masculine clitic. Moroccan Arabic has an epicene term «bnadm $(m)=$ person» which refers to both men and women. In fact, all epicenes in Moroccan Arabic are grammatically masculine. Interestingly, many Moroccans today use the feminine counterpart «bnadm-a» instead of «bnadm» (Ibid: 35, 36).

In general, feminine nouns are derived from masculine nouns. Attaching «-a» to masculine nouns almost invariably turns them feminine. This process of word formation is quite heavily exploited in professional nouns, (e.g, țbib (m)/ tbib-a (f)= physician) and in kinship terms as we saw above. Some female names are derived from male names. These names conforms to the productive rule that derives feminine words by attaching the feminine suffix «-a» to the masculine form. Consider the following pairs of given names, where the first name in the pair is masculine and the second is feminine: Safid/ Safida (Ibid: 36).

To summarize, in Moroccan Arabic: there are two grammatical genders (masculine and feminine) and two numbers (singular and plural); all nouns are either masculine or feminine; both singular and plural nouns have grammatical gender distinction; the unmarked grammatical gender is masculine; adjectives, verbs, pronouns, and prepositions agree with nouns in grammatical gender and number; adjectives always follow the nouns they modify; feminine nouns usually end in the feminine suffix «-a» and masculine nouns carry a zero suffix; in some cases, feminine nouns do not end in «-a» like body parts coming in pairs, in this case, the agreeing elements like adjectives provide information about the noun's grammatical gender; when the noun has natural gender such as kinship and non-kinship terms, its grammatical gender corresponds with it; there are two types of personal pronouns: dependent and independent. Both types have grammatical gender distinction; feminine professional nouns and female names are derived from masculine professional nouns and male names by adding «-a» to the end of them. Consequently, the grammatical gender assignment system of this language is formal, i.e. phonological and therefore overt. 


\section{Grammatical Gender in Hawrami}

Hawrami possesses two grammatical genders (masculine and feminine) and two numbers (singular and plural). All nouns are either masculine or feminine. The grammatical gender of the noun is determined by its final phone and stress position. It is noteworthy that only singular nouns have grammatical gender. Adjectives agreeing with the masculine nouns, end in consonant and the stressed vowels (-'i, -'a, -'a) and those agreeing with feminine nouns end in the unstressed vowel (-a) and the stressed vowel (-'e). In Hawrami, there are two definite articles («-aka» for masculine and «-ake» for feminine) and two indefinite articles («-ev» for masculine and «-eva» for feminine). As /v/ does not occur in final position, the indefinite article for masculine changes into /-ew/ in this position. Table 1 shows the formal markers of masculine and feminine nouns in Hawrami (Sadjadi, 2015).

Table 1: Formal Markers of Masculine and Feminine Nouns in Hawrami (Ibid)

\begin{tabular}{|c|c|}
\hline Masculine Noun & Feminine Noun \\
\hline 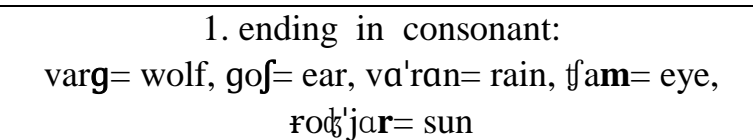 & $\begin{array}{l}\text { 1. ending in the unstressed vowels }(-i,-a) \text { and the } \\
\text { stressed vowel }(-\mathrm{e}) \text { : } \\
\text { '?avi= water, 'manga }=\text { moom, fo'te }=\text { fast }\end{array}$ \\
\hline 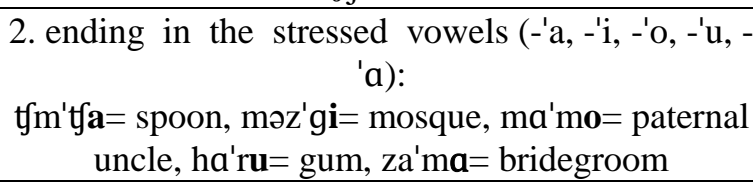 & $\begin{array}{l}\text { 2. ending in the stressed vowel }(-' a) \text { : } \\
\qquad a^{\prime} g a=\text { village }\end{array}$ \\
\hline $\begin{array}{c}\text { 3. ending in }(-j) \text { : } \\
\text { taj }=\text { tea, waj }=\text { suffering }\end{array}$ & $\begin{array}{c}\text { 3. ending in }(-\mathrm{j}) \text { : } \\
\text { maj= sheep, baj= quince }\end{array}$ \\
\hline
\end{tabular}

As it is observed in the table, both masculine and feminine nouns end in (-a) and (-i). What distinguishes between them is the position of stress; the nouns ending in these two stressed vowels are masculine and those ending in the unstressed ones are feminine. Moreover, both masculine and feminine nouns end in the stressed vowel (-'a) and consonant (-j). Most nouns ending in the stressed vowel (-'a) are masculine and most nouns ending in the consonant $(-\mathrm{j})$ are feminine, although there are some having the opposite grammatical gender among both nouns. In these cases, what determines the grammatical gender of the noun is the formal markers of the agreeing elements such as articles (definite and indefinite) and adjectives because articles and adjectives agree with nouns in grammatical gender. The following examples illustrate this point:

(4) a. ga'ła-j

leaf.MAS-GEN

'yellow leaf'

b. da'ga-j

village.FEM-GEN

'small village'

(5) a. tyaj-aka

tea.MAS-DA.MAS

'the tea'

b. maj-ake

sheep.FEM-DA.FEM

'the sheep'

As it is clear, the nouns in each pair end in the same phone. For determining the grammatical gender of the nouns, we should look at the agreeing elements (adjectives and articles). In (4a), the adjective (zarl) ends in the consonant ( $\mathrm{l}$ ) but in (4b), the adjective (wət'kle) ends in the stressed vowel (-'e). Thus, the nouns (ga'ła) in (4a) zard

yellow.MAS

wət'kle

small.FEM 
and (da'ga) in (4b) are masculine and feminine respectively. The nouns (tfaj) in (5a) and (maj) in (5b) are masculine and feminine with regard to their definite articles (-aka) and (-ake) respectively.

In addition to adjectives and articles, verbs and pronouns also agree with nouns in grammatical gender in Hawrami (Ibid).

There is correspondence between grammatical and natural gender in Hawrami. Thus, the male and female nouns including human nouns and kinship terms are grammatically masculine and feminine: ('zani= woman, pja $=$ man, $k J \mathbf{r}=$ boy, kna't $\mathbf{e}=$ girl, la'lo= maternal uncle, ma'mo= paternal uncle, 'matja $=$ paternal and maternal aunt, $\mathrm{Pa}^{\prime} \mathbf{d} \mathbf{a}=$ mother, $\operatorname{ta} \mathrm{t} \mathbf{t}=$ father). This is true for general human nouns and occupational titles: $(\mathrm{tgaftkar}(\mathrm{m}) /$ taft'kara $(\mathrm{f})=$ cook, nanpat $(\mathrm{m}) / \operatorname{nan}$ 'patfa $(\mathrm{f})=$ baker, nawa $(\mathrm{m}) /$ na'wa $\int \mathbf{a}(\mathrm{f})=$ patient). Loan words follow this rule too: $\left(\int \operatorname{ofir}(\mathrm{m}) / \int \mathrm{f}^{\prime}\right.$ ira $(\mathrm{f})=$ driver, doktor $(\mathrm{m}) /$ 'doktra $(\mathrm{f})=$ physician $)$. In fact, the masculine nouns are derived from feminine ones by adding unstressed $(-a)$ to the end of them.

Hawrami has two types of personal pronouns: dependent and independent. The third singular of independent subject and object pronouns are differentiated for grammatical gender. Both of them have two forms based on

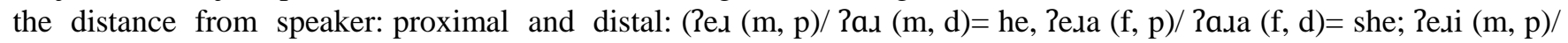
Rasi $(\mathrm{m}, \mathrm{d})=$ him, Reıe (f, p)/ Rase (f, d)= her). Dependent object pronouns are clitics that attach to transitive verbs in simple past (zero morpheme « $\emptyset$ for masculine and «'a-» for feminine), subjunctive past, subjunctive continuous past, present perfect, present perfect continuous, past perfect, past perfect continuous, perfect conditional, and continuous perfect conditional («'a-» for masculine and «-'e-» for feminine). The following sentences illustrate this point:

(6) a. ?avi-m

water.FEM-I

'I drank water.'

b. nan-əm

food.MAS-I

'I ate (food).'

(7) a. ?avi-m

water.FEM- I

'I had drunk water.'

b. nan-əm

food.MAS-I ward-a.

drink.PAS- FEM

ward-ø.

eat.PAS-MAS

warı-e-be.

eat.PP-FEM-had

ward-a-be.

eat.PP-MAS-had

'I had eaten (food).'

Some female names are derived from male names (only those ending in consonant) by attaching the feminine suffix (-a) to the masculine form: (ravin (m)/ ravina (f), njan (m)/ njana (f), razan (m)/ razana (f)).

In Hawrami, there are two masculine and feminine terms «bənja.əm= person» and «bənja.ıma=person» which refer to men and women respectively.

To summarize, in Hawrami: there are two grammatical genders (masculine and feminine) and two numbers (singular and plural); all nouns are either masculine or feminine; only singular nouns have grammatical gender distinction; the unmarked grammatical gender is masculine; adjectives, verbs, pronouns, and articles (definite and indefinite) agree with nouns in grammatical gender and number; adjectives follow the nouns they modify; the grammatical gender of the noun is determined by its final phone and stress position; in some cases, both masculine and feminine nouns end in the same formal markers (the stressed vowel (-'a) and consonant $(-j)$ ). In these cases, the agreeing elements like adjectives and articles provide information about the noun's grammatical gender; when the noun has natural gender such as kinship and non-kinship terms, its grammatical gender corresponds with it; there are two types of personal pronouns: dependent and independent. Both types have grammatical gender distinction (only in the third singular); feminine professional nouns and female names 
are derived from masculine professional nouns and male names by adding «-a» to the end of them. Consequently, the grammatical gender assignment system of this language is formal, i.e. phonological and therefore overt.

\section{Conclusion}

As mentioned, the aim of this article was to study the similarities and differences in grammatical gender between Arabic and Hawrami, belonging to two different language families, i.e. Semitic and Indo-European, within the framework of contrastive analysis.

Data contrast indicates that in both languages: there are two grammatical genders (masculine and feminine) and two numbers (singular and plural); all nouns are either masculine or feminine; the grammatical gender of the noun is determined by its final phone (and stress position in Hawrami); the unmarked grammatical gender is masculine; adjectives, verbs, and pronouns agree with nouns in grammatical gender; adjectives follow the nouns they modify; in cases that the nouns have the same formal markers of grammatical gender, the agreeing elements like the adjectives (and articles in Hawrami) help the determination of the grammatical gender of the nouns; when the noun has the natural gender, its grammatical gender corresponds with it: there are two types of personal pronouns: dependent and independent. Both types have grammatical gender distinction; professional feminine nouns and female names are derived from professional masculine nouns and male names by adding «-a» to the end of them. Consequently, the grammatical gender assignment system of both languages is formal, i.e. phonological and therefore overt.

There are also some differences between the two languages: in Hawrami, only singular nouns have grammatical gender distinction, while in Arabic, both singular and plural nouns have this distinction. In Hawrami, articles (definite and indefinite) agree with nouns in grammatical gender, whereas in Arabic, they do not agree. Moreover, preposition agree with nouns in grammatical gender in Arabic, while they do not agree in Hawrami. In Hawrami, only the third singular of dependent and independent personal pronouns have grammatical gender distinction. As some of Hawrami speakers live in Iraq whose official language is Arabic and also the majority of them are Muslims and Arabic is the Muslims' holy languge, the results of the research can be used in language (Arabic) learning and comparative and historical linguistics.

\section{References}

Corbett, G. (1991). Gender. Cambrige: Cambridge University Press.

Hellinger, M. and H. Bußmann (2001). Gender across languages (Vol. 1). Philadelphia: John Benjamins Publishing Company.

Sadjadi, M. (2015). Grammatical gender in the Hawrami language (in Persian). Marivan: Avin.

Tallerman, M. (2011). Understanding syntax. London: Hodder Education.

www.unesco.org/languages-atlas/ 